\title{
Cost-effectiveness of posaconazole versus fluconazole or itraconazole in the prevention of invasive fungal infections among high-risk neutropenic patients in Spain
}

Santiago Grau ${ }^{1 *}$, Rafael de la Cámara ${ }^{2}$, Francisco J Sabater ${ }^{3}$, Isidro Jarque ${ }^{4}$, Enric Carreras ${ }^{5}$, Miguel A Casado ${ }^{6}$ and Miguel A Sanz ${ }^{4}$

\begin{abstract}
Background: We evaluated the cost-effectiveness of posaconazole compared with standard azole therapy (SAT; fluconazole or itraconazole) for the prevention of invasive fungal infections (IFI) and the reduction of overall mortality in high-risk neutropenic patients with acute myelogenous leukaemia (AML) or myelodysplastic syndromes (MDS). The perspective was that of the Spanish National Health Service (NHS).

Methods: A decision-analytic model, based on a randomised phase III trial, was used to predict IFI avoided, lifeyears saved (LYS), total costs, and incremental cost-effectiveness ratio (ICER; incremental cost per LYS) over patients' lifetime horizon. Data for the analyses included life expectancy, procedures, and costs associated with IFI and the drugs (in euros at November 2009 values) which were obtained from the published literature and opinions of an expert committee. A probabilistic sensitivity analysis (PAS) was performed.

Results: Posaconazole was associated with fewer IFI (0.05 versus 0.11 ), increased LYS (2.52 versus 2.43), and significantly lower costs excluding costs of the underlying condition $(€ 6,121$ versus $€ 7,928)$ per patient relative to SAT. There is an $85 \%$ probability that posaconazole is a cost-saving strategy compared to SAT and a $97 \%$ probability that the ICER for posaconazole relative to SAT is below the cost per LYS threshold of $€ 30,000$ currently accepted in Spain.
\end{abstract}

Conclusions: Posaconazole is a cost-saving prophylactic strategy (lower costs and greater efficacy) compared with fluconazole or itraconazole in high-risk neutropenic patients.

\section{Background}

Patients with neutropenia as a result of chemotherapy for acute myelogenous leukaemia (AML) or myelodysplastic syndrome (MDS) are at high risk of developing invasive fungal infection (IFI) [1-7]. Early diagnosis and treatment of IFI are difficult and, as such, are associated with high mortality rates in neutropenic patients. Hence, prophylaxis of IFI has become a commonly used strategy to reduce overall morbidity-mortality rates in patients with haematologic malignancies [8].

\footnotetext{
* Correspondence: sgrau@parcdesalutmar.cat

'Hospital del Mar, Barcelona, Spain

Full list of author information is available at the end of the article
}

Posaconazole is a new-generation oral azole [9] that has been demonstrated to be superior to standard azole therapy (SAT; fluconazole or itraconazole) in preventing IFI and reducing overall mortality in high-risk neutropenic patients [10]. In a recent study, posaconazol was shown not only to be as efficacious as fluconazole in the prevention of IFI but also superior to fluconazole in the prevention of invasive aspergilosis (proven or probable) in haematopoietic stem cell transplant patients with graft-versus-host disease (GHVD) [11]. As such, posaconazole is recommended in major clinical guidelines [12-15] as prophylaxis for neutropenic patients with AML or MDS (category 1/A-I).

\section{Ciomed Central}

(c) 2012 Grau et al; licensee BioMed Central Ltd. This is an Open Access article distributed under the terms of the Creative Commons Attribution License (http://creativecommons.org/licenses/by/2.0), which permits unrestricted use, distribution, and reproduction in any medium, provided the original work is properly cited. 
From the National Health Service (NHS) point of view, the financial sustainability of new health interventions is a fundamental priority due to the limitation of the financial resources [16]. Consequently, the authorities responsible for health-care provision require that new therapeutic or preventative alternatives bear information regarding their efficacy, safety, therapeutic usefulness and efficiency (cost-effectiveness) [17]. In this sense, the financial burden of IFI is consistently high, essentially in high-risk neutropenic patients and those who require a protracted stay in the intensive care unit [18-23]. The economic impact of diagnosis and treatment of IFI is related to the cost of the acquisition of the anti-fungal agent, the extra costs of hospitalisation, the cost of diagnostic tests, laboratory analyses and complementary tests, the diagnosis and treatment of the adverse effects of the treatment, the management of the therapeutic failures, and relapses that require the administration of second-line anti-fungal agents [24,25]. Disease burden and high mortality rates oblige health authorities to be aware of efficient anti-fungal prophylaxis in patients at high risk of suffering IFI such as, for example, patients with neutropenia following intensive chemotherapy. However, despite several studies having shown efficacy in specific groups of neutropenic patients at high risk of IFI [26-28], there is a relative dearth of economic evaluations of prophylactic anti-fungal agents.

Posaconazole has been shown to be more efficacious than SAT for the prophylaxis of AML or MDS among high-risk neutropenic patients. However, the cost of the drug is higher than fluconazole and itraconazole. Therefore, the objective of this study was to evaluate the costeffectiveness of posaconazole compared to SAT for the prevention of IFI in patients with AML or MDS who are at high risk of developing an IFI as a result of chemotherapy-induced neutropenia. The perspective was the Spanish NHS, which is a system of universal healthcare provision for 45 million citizens. The data for the present analyses were based on the randomised phase III trial conducted by Cornely et al [10]. The outcomes of the analyses would be useful not only from the Spanish perspective but also for those European countries with a similar health service to that in Spain.

\section{Methods}

A decision analytic model was constructed to evaluate the cost-effectiveness of posaconazole versus SAT in preventing IFI in high-risk neutropenic patients. Evidence of clinical effectiveness of both alternatives was based on a randomised study [10] that compared the efficacy and safety of posaconazole with that of SAT as prophylaxis for patients with protracted neutropenia. The trial was conducted following good clinical practice guidelines and the Declaration of Helsinki of the World
Medical Association. It was published on clinicaltrials. gov (NCT00044486) and it was approved by the institutional review board or ethics committee at each participating center. The numbers of IFI avoided and the number of life years saved (LYS) with each of the alternative therapies were used to measure the economical benefits. Similarly, we assessed the total cost of treatment including the costs of the prophylactic anti-fungal drug, preparation and administration of posaconazole or SAT, and the treatment of the IFI cases in each group. Based on this information we calculated the incremental cost-effectiveness ratio of the most effective strategy versus the least effective, i.e. the incremental cost for each IFI avoided and the cost for each LYS with posaconazole compared to fluconazole or itraconazole. Model assumptions and parameters of resource use were decided in consultation with an advisory group. The perspective adopted was that of the Spanish NHS, with costs and benefits discounted at an annual rate of $3 \%$ after the $1^{\text {st }}$ year of treatment [29].

\section{Decision-analytical model}

Using Microsoft Excel 2003 for Windows ${ }^{\circledR}$, an interactive economic evaluation model was developed to assess the clinical benefits obtained with each therapeutic option, and to estimate the associated health costs of patients receiving prophylaxis with posaconazole or SAT for the prevention of IFI. The costs associated with the prevention or treatment of the IFI that may arise in each of the treatment groups were calculated.

The model consists of two integrated parts. The first part is a decision tree (Figure 1) that reproduces, in the 100 days post-treatment, the clinical outcomes for the patients treated with posaconazole or with SAT in a clinical trial comparing both strategies [10]. The decision tree starts with a decision node that describes the prophylaxis selection for IFI, either posaconazole or SAT. After prophylaxis initiation, the patient can develop IFI according to the probabilities described in the clinical trial (Table 1). The model also takes into account the probability of survival or death once the IFI occurrs. The model takes into account not only the patients who do not develop IFI but also those who survive the IFI, as well as the probability of death from other causes not related to the IFI during the initial 100 days of prophylaxis.

The second part of the model consists of an additional Markov model [30], which extrapolates the results of the clinical trial and simulates the progression of the disease over the long-term course of the patients' life, i.e. beyond the first 100 days of prophylaxis. The patients who survive the initial 100 days enter into this Markov model which, following the monthly cycles, projects the risk of death from the underlying disease (AML or 


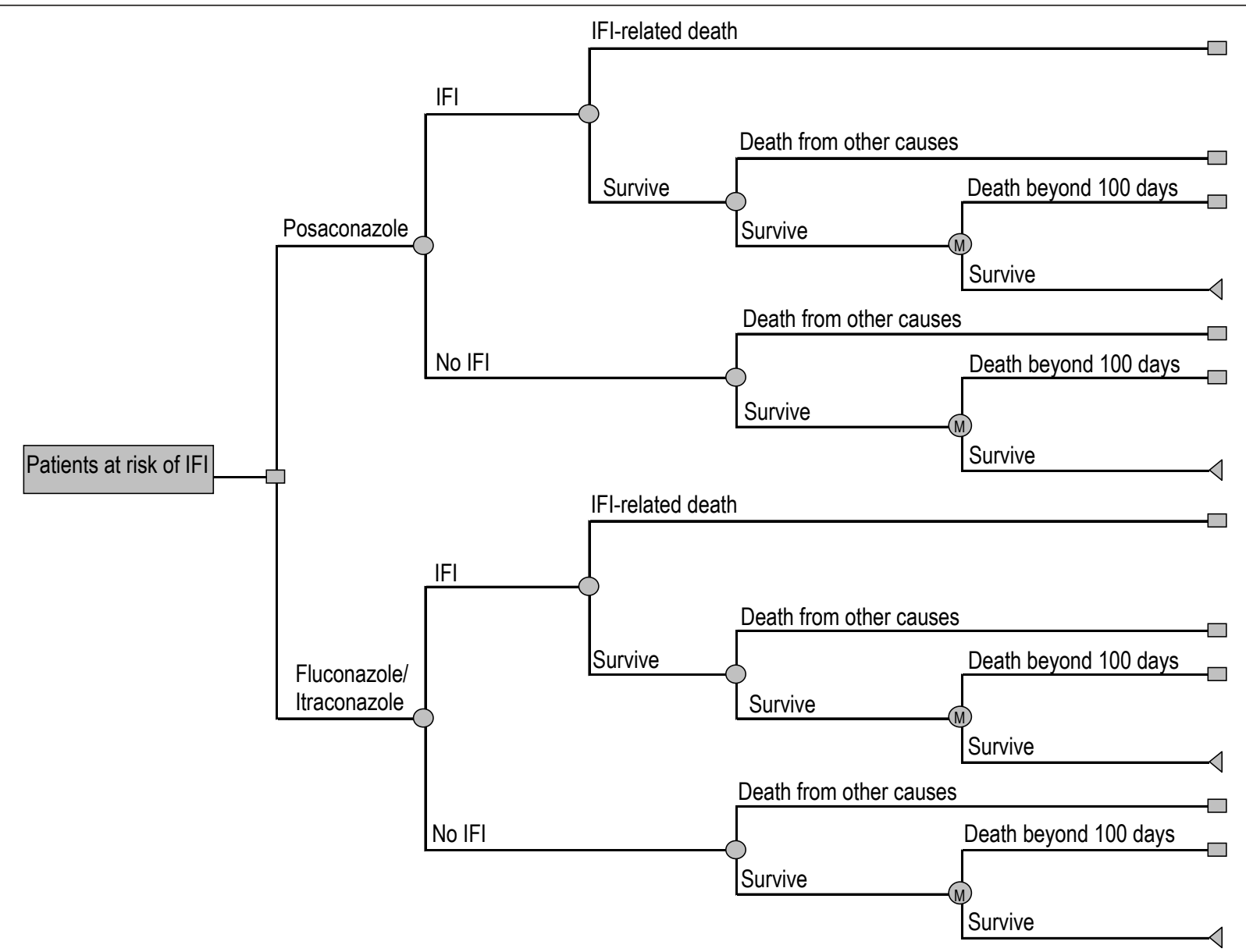

Figure 1 Decision-tree model of posaconazole versus SAT (standard azole treatment; fluconazole or itraconazole) for the prevention of invasive fungal infection (IFI) among high-risk neutropenic patients. $M=$ Markov model.

MDS) or from whatever cause, independently of whether or not the patients had had an IFI [31]. In this case, the relative survival values obtained from the literature were 0.21 for AML [32] and 0.08 for MDS [33] or other causes (Table 1).

\section{Clinical data}

Clinical efficacy data used in the analyses were collected from a clinical trial that compared posaconazole versus fluconazole or itraconazole in the prevention of IFI in high-risk patients with neutropenia [10]. This was a prospective, randomised, multicenter study in which 304 patients were assigned to receive posaconazole and 298 patients SAT (fluconazole in $81 \%$ and itraconazole in 19\% of patients). The patients received $200 \mathrm{mg}$ posaconazole in oral suspension three times a day (total daily dose: 600 $\mathrm{mg}$ ), $400 \mathrm{mg}$ fluconazole in oral suspension once a day (total daily dose: $400 \mathrm{mg}$ ) or $200 \mathrm{mg}$ itraconazole in oral solution twice a day (total daily dose: $400 \mathrm{mg}$ ). Prophylaxis was administered with each chemotherapy cycle, and was continued until recovery from neutropenia and complete remission, or until occurrence of an IFI, or for up to 12 weeks post-randomisation, whichever came first. Patients were followed-up for 100 days post-randomisation, and for 30 days after the last dose of the study drug administered during the last chemotherapy cycle. Proven or probable IFI occurred during the treatment phase in 7 of the 304 patients (2\%) in the posaconazole group and in 25 of the 298 patients (8\%) in the SAT group; absolute reduction in the posaconazole group of $-6 \%(95 \% \mathrm{CI}:-9.7$ to $-2.5 \%$; $<0.001$ ). During the 100 -days of the post-randomisation period, 14 of 304 patients (4.6\%) in the posaconazole group had a proven or probable fungal infection, compared to 33 of the 298 patients $(11 \%)$ in the SAT group $(\mathrm{p}=0.003)$ (Table 1$)$. Two patients $(1 \%)$ in the posaconazole group had invasive aspergillosis versus 20 $(7 \%)$ in the SAT group $(\mathrm{p}<0.001)$. The mean $( \pm$ SD) time to IFI was $41 \pm 26$ days in the posaconazole group and 25 \pm 26 days in the SAT group. Survival was significantly longer among patients treated with posaconazole than among patients in the SAT group. Of the 304 patients in the posaconazole group, 49 (16\%) died during the study 
Table 1 Clinical data parameters used in the model; base-case and sensitivity analysis

\begin{tabular}{|c|c|c|c|c|c|c|}
\hline \multicolumn{7}{|c|}{ Sensitivity analysis } \\
\hline & \multicolumn{2}{|r|}{ Base-case estimate } & \multirow[t]{2}{*}{ Deterministic } & \multicolumn{3}{|c|}{ Probabilistic } \\
\hline & & Reference & & Reference & Distribution & SD \\
\hline \multicolumn{7}{|c|}{ Within first 100 days of prophylaxis } \\
\hline \multicolumn{7}{|c|}{ Probability of an invasive fungal infection (IFI) } \\
\hline Posaconazole & 0.05 & Cornely[10] & $0.0344-0.0573$ & Assumption & Beta & 0.0120 \\
\hline SAT & 0.11 & Cornely[10] & $0.0825-0.1375$ & Assumption & Beta & 0.0181 \\
\hline \multicolumn{7}{|c|}{ Probability of an IFI-related death } \\
\hline Posaconazole & 0.36 & Cornely[10] & $0.2678-0.4464$ & Assumption & Beta & 0.1247 \\
\hline$\overline{\text { SAT }}$ & 0.48 & Cornely[10] & $0.3636-0.6060$ & Assumption & Beta & 0.0857 \\
\hline \multicolumn{7}{|c|}{ Probability of death from other causes (non IFI-related) } \\
\hline Posaconazole & 0.16 & Cornely[10] & $0.1185-0.1975$ & Assumption & Beta & 0.0148 \\
\hline SAT & 0.16 & Cornely[10] & $0.1185-0.1975$ & Assumption & Beta & 0.0148 \\
\hline \multicolumn{7}{|c|}{ After first 100 days of prophylaxis } \\
\hline \multicolumn{7}{|c|}{ Relative survival associated with acute myelogenous leukaemia (AML) } \\
\hline$\overline{\mathrm{IFI}}$ & 0.21 & $\mathrm{NCl}[32]$ & $0.16-0.26$ & Assumption & Gamma & 0.000 \\
\hline No IFI & 0.21 & $\mathrm{NCl}[32]$ & $0.16-0.26$ & Assumption & Gamma & 0.000 \\
\hline \multicolumn{7}{|c|}{ Relative survival associated with myelodysplastic syndrome (MDS) } \\
\hline$\overline{\mathrm{IFI}}$ & 0.08 & Kantarjian[33] & $0.06-0.10$ & Assumption & Gamma & 0.000 \\
\hline No IFI & 0.08 & Kantarjian[33] & $0.06-0.10$ & Assumption & Gamma & 0.000 \\
\hline
\end{tabular}

SAT standard azole treatment (fluconazole $81 \%$ patients or itraconazole $19 \%$ patients) SD standard deviation

period, as did 67 of 298 patients (22\%) in the SAT group $(p=0.048)$. The incidence of adverse events was similar among both treatment groups, $52 \%$ in the posaconazole group vs $59 \%$ in the SAT group [10]. Kaplan-Meier analysis of the all-cause time-to-death at the end of the 100-day period post-randomisation showed a significant survival benefit in favour of posaconazole over fluconazole or itraconazole $(p=0.04)$. The data on efficacy of both therapeutic options are summarised in Table 1.

\section{Patient population}

The economic evaluation was performed in patients with neutropenia resulting from chemotherapy for AML or MDS and who were at high risk of developing an IFI. The patient population studied correspond to the patients at baseline in the study by Cornely et al [10].

\section{Cost estimation}

To determine the costs and benefits of the treatments under comparison, the perspective used was that of the Spanish NHS and, as such, only the following direct health costs were considered (Table 2).

- Costs of the prophylactic treatment used. The cost of the pharmaceutical preparation (exfactory price) was obtained from the medication database of the General Spanish Council of Pharmacists [34]. The model used the values of daily dosage and treatment duration of posaconazole, fluconazole or itraconazole as established in the clinical trial by Cornerly et al [10].

- Cost of preparation, administration and monitoring the anti-fungal treatment. Nurse time cost of 15, 5 and $10 \mathrm{~min}$ for the preparation of posaconazole, fluconazole and itraconazole, respectively, and the costs of the three drugs requiring hepatic function monitoring twice a week over the period of prophylaxis. The unit costs of these resources were obtained from the SOIKOS database [35] and updated to values in euros of November 2009.

- Cost of IFI management. The cost per IFI of $€ 67,984$ was considered for either treatment option. This value was obtained from the 2005 update of the cost of IFI in an economic evaluation of voriconazol versus conventional amphotericin $\mathrm{B}$ in the treatment of invasive aspergillosis in Spain [36]. The direct costs of the drug treatment, anti-fungal medication, hospitalisation and laboratory tests were included in this evaluation.

The model did not include the cost of the adverse events nor the cost of management of the underlying disease (AML or MDS) since these costs would be common and similar to both treatment groups. All the costs are expressed in terms of euros at November 2009 values. 
Table 2 Unitary costs* and treatment duration parameters used in the model; base-case and sensitivity analysis

\begin{tabular}{|c|c|c|c|c|c|c|}
\hline & \multicolumn{2}{|c|}{ Base-case estimate } & \multicolumn{4}{|c|}{ Sensitivity analysis } \\
\hline & & & \multicolumn{2}{|l|}{ Deterministic } & \multicolumn{2}{|l|}{ Probabilistic } \\
\hline & \multicolumn{2}{|r|}{ Reference } & & Reference & Distribution & SD \\
\hline \multicolumn{7}{|c|}{ Total treatment cost per day } \\
\hline Posaconazole & 103.69 & & $77.77-129.61$ & Assum. & Gamma & 0.000 \\
\hline Fluconazole & 16.93 & & $12.70-21.16$ & Assum. & Gamma & 0.000 \\
\hline Itraconazole & 21.85 & & $16.39-27.31$ & Assum. & Gamma & 0.000 \\
\hline \multicolumn{7}{|c|}{ Drug cost per day } \\
\hline Posaconazole & 90.00 & CGCOF[34] & & & & \\
\hline Fluconazole & 8.00 & CGCOF[34] & & & & \\
\hline Itraconazole & 8.95 & CGCOF[34] & & & & \\
\hline \multicolumn{7}{|c|}{ Preparation, administration and monitoring treatment cost per day } \\
\hline Posaconazole & 13.69 & Gisbert[35] & & & & \\
\hline Fluconazole & 8.93 & Gisbert[35] & & & & \\
\hline Itraconazole & 12.90 & Gisbert[35] & & & & \\
\hline \multicolumn{7}{|c|}{ Treatment duration } \\
\hline Posaconazole & 29 & Cornely[10] & & & & \\
\hline Fluconazole & 24 & Cornely[10] & & & & \\
\hline Itraconazole & 29 & Cornely[10] & & & & \\
\hline \multicolumn{7}{|c|}{ Cost of an invasive fungal infection (IFI) } \\
\hline In-patient cost & 67,984 & Grau[36]* & $50,988-84,980$ & Assum. & Gamma & \\
\hline
\end{tabular}

*In euros at November 2009 prices

\section{Cost-effectiveness analysis}

The time horizon of the study was 100 days, and lifetime of the patient. Hence, for each prophylactic alternative we calculated the number of IFI avoided in 100 days, and the number of LYS over the long-term of the patient's life. Similarly, we obtained the total cost for each treatment group including the costs of the prophylaxis (drug, preparation and administration) and of the treatment of the IFI that may arise. From these results we calculated the incremental cost per IFI avoided, and the incremental costs for each LYS with the more effective treatment (in the present case posaconazole), compared to the less effective SAT (fluconazole or itraconazole).

If the result of the modelling indicated that one of the therapeutic options was more efficacious (less IFI or greater number of LYS) and, in turn, had a lower total cost compared to the other option, this would establish therapeutic dominance. If, as well, a saving is produced relative to the alternative option, then it would be unnecessary to calculate the incremental cost-effectiveness ratio [37]. If, on the other hand, one of the options evaluated was more efficacious but more costly than the alternative, the incremental cost-effective ratio is calculated relative to the less costly alternative. In the analysis we considered that one of the strategies is efficient if the cost per LYS is less than the threshold of efficiency currently accepted in Spain, and which has been established at $<€ 30,000$ euros per LYS [38].

\section{Sensitivity analysis}

We performed a deterministic univariate sensitivity analysis with the objective of assessing the robustness of the model, and the consistency of the assumptions used in the model. The parameters modified were those that were most relevant in the model or those with the greatest uncertainty. These were the efficacy of prophylaxis, the risk of death from IFI, and the cost of treatment of the IFI with a value of $75 \%$ or $125 \%$ of the value used in the base case estimations, except for the probability of experiencing an IFI that a wider range was considered (Tables 1 and 2). Further, a sensitivity analysis was performed applying a discount rate of $0 \%$ and $5 \%$ to the costs and the outcomes [29].

A multivariate probabilistic sensitivity analysis (PSA) was also performed using 1,000 second-order Monte Carlo simulations. The assumptions of the model were randomly modified based on probability functions described in Tables 1 and 2 .

\section{Results}

\section{Base case analysis}

In the base case over the 100 first days of prophylaxis, the IFI per patient in the SAT group was 0.11 versus 0.05 in the posaconazole group (Table 3), i.e. posaconazole avoided a mean of 0.06 IFI per patient.

In the projection of progression of the disease over the life-term of the patient, the treatment with posaconazole achieved better clinical results, increasing the life 
Table 3 Results of the base case of posaconazole versus SAT in the prevention of IFI among high-risk neutropenic patients

\begin{tabular}{lcclll}
\hline Strategy & Total costs* & IFI events & LYS & ICER (cost per IFI avoided) & ICER (cost per LYS) \\
\hline Posaconazole & 6,121 & 0.05 & 2.52 & & \\
\hline SAT & 7,928 & 0.11 & 2.43 & & \\
\hline Difference $^{\dagger}$ & $-1,807$ & -0.06 & 0.09 & Dominant $^{\ddagger}$ & Dominant $^{\ddagger}$ \\
\hline
\end{tabular}

*In euros at November 2009 prices

${ }^{\dagger}$ Difference between posaconazole and SAT

${ }^{\ddagger}$ Dominant strategy: posaconazole has lower cost and higher efficacy (measured as IFI avoided and LYS) compared to SAT (standard azole treatment: fluconazole $81 \%$ patients/itraconazole $19 \%$ patients)

expectancy of the patients by 2.52 years, compared to a mean increase of 2.43 years in the SAT group. As such, posaconazole produces an increase of 0.09 in LYS (Table 3).

The total costs of treatment in the SAT group was $€ 7,928$ per patient (Table 3 ), $€ 450$ related to the prophylactic drug used in avoiding IFI (drug costs, administration and monitoring) and $€ 7,478$ associated with the costs of treatment of FI in the patients with neutropenia. In the group of patients treated with posaconazole, the average cost per patient was $€ 6,121$, of which $€ 3,007$ was due to the anti-fungal treatment and $€ 3,114$ for the management of IFI. The final result was a saving of $€ 1,807$ per patient treated with posaconazole compared to the patients who received SAT prophylaxis with fluconazole or itraconazole.

Table 3 summarises the costs and the benefits (IFI avoided and LYS) obtained for each treatment group. The prophylaxis with posaconazole is the dominant strategy compared to prophylaxis with SAT i.e. the clinical outcomes were better and with lower overall cost.

\section{Deterministic sensitivity analysis}

The results of the univariate deterministic sensitivity analysis are summarised in Table 4. All the outcomes are consistent with the base case, i.e. for all the variations of the parameters introduced into the model; posaconazole is the dominant strategy over that of SAT.

\section{Probabilistic sensitivity analysis}

The results of the PSA show that there is a probability of $85 \%$ that posaconazole is a cost-saving strategy, compared to SAT (Figure 2) and a probability of $97 \%$ that the incremental cost-effectiveness ratio for posaconazole versus SAT is below the estimated $€ 30,000$ per LYS threshold currently accepted in Spain (Figure 3).

A final sensitivity analysis was performed, to find at what values results changed. Only when the probability

Table 4 Results of the deterministic sensitivity analysis of posaconazole versus SAT in the prevention of IFI among high-risk neutropenic patients

\begin{tabular}{|c|c|c|c|}
\hline Parameter & Sensitivity analysis value & ICER (cost per IFI avoided) & ICER (cost per LYS) \\
\hline \multirow[t]{2}{*}{ Probability of IFI; Posaconazole } & 0.025 & Dominant* & Dominant* \\
\hline & 0.075 & Dominant* & Dominant* \\
\hline \multirow[t]{2}{*}{ Probability of IFI; SAT } & 0.075 & Dominant* & Dominant* \\
\hline & 0.15 & Dominant* & Dominant* \\
\hline \multirow[t]{2}{*}{ Probability of an IFI-related death; Posaconazole } & 0.2678 & Dominant* & Dominant* \\
\hline & 0.4464 & Dominant* & Dominant* \\
\hline \multirow[t]{2}{*}{ Probability of an IFI-related death; SAT } & 0.3636 & Dominant* & Dominant* \\
\hline & 0.6060 & Dominant* & Dominant* \\
\hline Probability of death from other & 0.1185 & Dominant* & Dominant* \\
\hline causes; non IFI-related & 0.1975 & Dominant* & Dominant* \\
\hline \multirow[t]{2}{*}{ Relative survival; AML } & 0.16 & Dominant* & Dominant* \\
\hline & 0.26 & Dominant* & Dominant* \\
\hline \multirow[t]{2}{*}{ Relative survival; MDS } & 0.06 & Dominant* & Dominant* \\
\hline & 0.10 & Dominant* & Dominant* \\
\hline \multirow[t]{2}{*}{ Total treatment cost per day; Posaconazole } & 77.77 & Dominant* & Dominant* \\
\hline & 129.61 & Dominant* & Dominant* \\
\hline Total treatment cost per day; Fluconazole & 12.70 & Dominant* & Dominant* \\
\hline
\end{tabular}


Table 4 Results of the deterministic sensitivity analysis of posaconazole versus SAT in the prevention of IFI among high-risk neutropenic patients (Continued)

\begin{tabular}{llll}
\hline & 21.16 & Dominant* $^{*}$ & Dominant* $^{*}$ \\
\hline Total treatment cost† per day; Itraconazole & 16.39 & Dominant* & Dominant* \\
\cline { 2 - 4 } & 27.31 & Dominant* $^{*}$ & Dominant* $^{*}$ \\
\hline Discount rate for costs and benefits & $0 \%$ & Dominant* $^{*}$ & Dominant* $^{*}$ \\
\cline { 2 - 4 } & $5 \%$ & Dominant* $^{*}$ & Dominant $^{*}$ \\
\hline
\end{tabular}

*Dominant strategy: posaconazole has lower cost and higher efficacy (measured as IFI avoided and LYS) compared to SAT (standard azole treatment: fluconazole/ itraconazole)

${ }^{\dagger}$ In euros at November 2009 prices

of experiencing an IFI was identical in both groups, SAT was dominant over posaconazole treatment due to lower treatment costs. The treatment with posaconazole would not be more cost-effective if the incremental benefit over SAT was reduced from $6 \%$ to $2 \%$, as the ICER would be higher than $€ 30,000$.

\section{Discussion}

The findings from this study show that, from the perspective of the Spanish NHS, posaconazole is more effective than standard azoles (in the present case fluconazole or itraconazole) in preventing proven or probable IFI. The outcome is a reduction in overall mortality and a longer IFI-free survival among high-risk neutropenic patients with AML or MDS. Under most conditions in the model, posaconazole is the dominant strategy compared to SAT, i.e. patients who are treated with posaconazole have avoided a greater number of IFI with a higher survival rate while, at the same time, have lower total costs compared to patients receiving SAT. Deterministic sensitivity analyses showed that the modification of key parameters of the model had very little impact on the cost-effectiveness of posaconazole and, as such, the model is considered consistent in all the established assumptions.

Some limitations of the study need to be taken into account when interpreting these results. Firstly, the data on efficacy of the two therapeutic alternatives evaluated were obtained from a single clinical trial [10] so the differences in frequency and distribution of fungal species

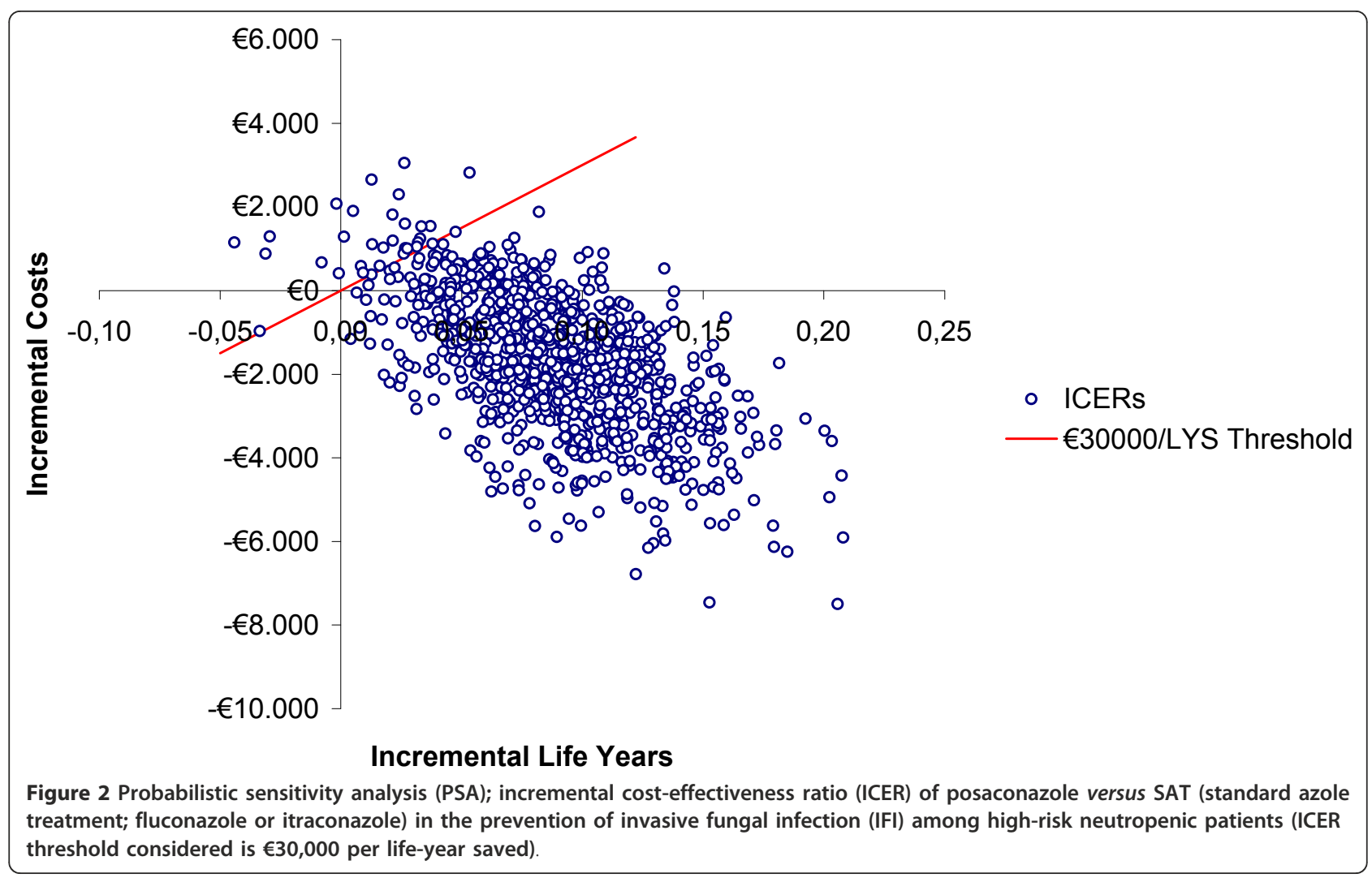




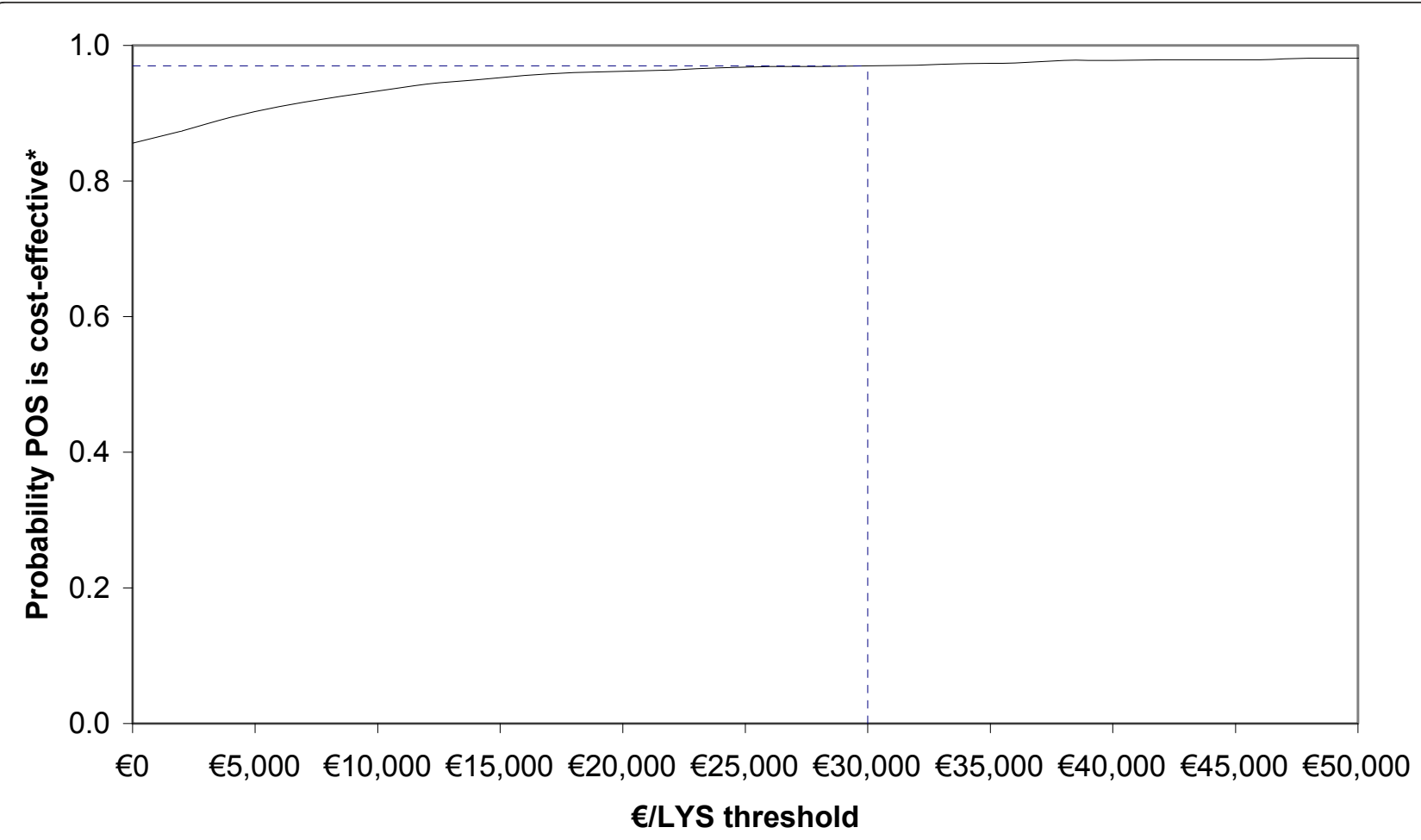

Figure 3 Cost-effectiveness acceptability curve; probability that posaconazole is cost-effective relative to SAT (standard azole treatment; fluconazole or itraconazole).

in real clinical setting could affect the efficacy results reported. Also, the data on resource use in the IFI were estimated from the published literature and, in a retrospective manner, by a panel of experts (authors of this manuscript). However, a probabilistic sensitivity analysis was conducted to evaluate the level of uncertainty associated with the inputs and assumptions of the model and, as well, to determine the interactions between the variables analysed. This analysis showed that there is an $85 \%$ probability that posaconazole is a cost-saving strategy compared to SAT and that the probability that the incremental cost-effectiveness ratio for posaconazole versus SAT is below the accepted threshold in Spain (currently $€ 30,000$ per LYS) is $98 \%$. However, with regards to external validity required by decision makers, it would be of considerable interest to evaluate whether these results are transferable to other settings. There may be further doubts regarding the benefits encountered in the clinical trial (the data from which were used in the present model) and whether these outcomes would apply to patients treated in routine clinical practice. On the other hand, the quality-of-life related to health in the outcomes of the patients treated with posaconazole or SAT was not taken into account, nor was the cost of the management of adverse events. However, in the referenced clinical trial [10], the incidence of adverse events was similar in both treatment groups. Similarly, the costs of management of the underlying diseases were not incorporated in the model since these were considered to be equal in the two alternative treatments and, consequently, would not have an impact on the final outcomes of the analyses.

Although our results are only valid for the Spanish National Health Care System due to the local nature of costs, our findings are in line with previous costeffectiveness analyses of posaconazole in the prevention of IFI among high-risk neutropenic patients with AML or MDS, based on Cornely study [10], conducted in other European countries and in the USA. All the cost-effectivenes analyses followed similar methodology and show that the incremental cost per LYS of posaconazole versus SAT is below the threshold commonly accepted in each of the countries as ceiling threshold for determining society's willingness to pay for a treatment, even when it is a dominant strategy (cost-saving) [28,39-43].

\section{Conclusion}

Our results suggest that prophylactic posaconazole in neutropenic patients with acute myelogenous leukaemia or myelodysplastic syndromes could potentially increase patient life expectancy and reduce the overall healthcare budget. 


\section{Acknowledgements}

The authors thank Amy O'Sullivan of i3/nnovus for programming the model. This study received an unconditional grant from Schering-Plough. Authors had independence from the funding body in study design, analysis and interpretation of the data, report writing and submission for publication.

\section{Author details}

${ }^{1}$ Hospital del Mar, Barcelona, Spain. ${ }^{2}$ Hospital de la Princesa, Madrid, Spain. ${ }^{3}$ Health Economics and Outcomes Research IMS Health, Madrid, Spain. ${ }^{4}$ Hospital Universitario La Fe, Valencia, Spain. ${ }^{5}$ Hospital Clinic, Barcelona, Spain. ${ }^{6}$ Pharmacoeconomics \& Outcomes Research Iberia, Madrid, Spain.

\section{Authors' contributions}

SG, RC, MAS, EC and IJ participated in data interpretation and writing the manuscript. MAC participated in study concept, designing the study, data interpretation and writing the manuscript. FJS participated in study concept. All the authors read and approved the final manuscript.

\section{Competing interests}

R. de la Cámara, E. Carreras, M.A. Sanz and I. Jarque: have received honoraria for speaking at symposia organised on behalf of Pfizer, Merck Sharp \& Dohme (MSD), Schering-Plough and Gilead Science and has sat on advisory boards for antifungal agents on behalf of MSD, Schering-Plough, Pfizer and Gilead; S. Grau: has received honoraria for speaking at symposia organised on behalf of Pfizer; M.A. Casado has served as an external consultant for Schering-Plough S.A; F.J. Sabater was an employee of Schering-Plough at the moment of manuscript first submission.

Received: 12 September 2011 Accepted: 3 April 2012 Published: 3 April 2012

\section{References}

1. Ascioglu S, de Pauw BE, Meis JF: Prophylaxis and treatmentof fungal infections associated with haematological malignancies. Int J Antimicrob Agents 2000, 15:159-168.

2. Bow EJ, Laverdière M, Lussier N, Rotstein C, Cheang MS, loannou S: Antifungal prophylaxis for severely neutropenic chemotherapy recipients: a meta-analysis of randomized controlled clinical trials. Cancer 2002, 94:3230-3246.

3. Robenshtok E, Gafter-Gvili A, Goldberg E, Weinberger M, Yeshurun M, Leibovici $L$, et al: Antifungal prophylaxis in cancer patients after chemotherapy or hematopoietic stem-cell transplantation: systematic review and meta-analysis. J Clin Oncol 2007, 25:5471-5489.

4. Maertens J, Buve K, Anaissie E: Broad-spectrum antifungal prophylaxis in patients with cancer at high risk for invasive mold infections: counterpoint. J Natl Compr Canc Netw 2008, 6:183-189.

5. Gudlaugsson O, Gillespie S, Lee K, Vande Berg J, Hu J, Messer S, et al: Attributable mortality of nosocomial candidemia, revisited. Clin Infect Dis 2003, 37:1172-1177.

6. Enoch DA, Ludlam HA, Brown NM: Invasive fungal infections: a review of epidemiology and management options. J Med Microbiol 2006, 55:809-818.

7. Zaoutis TE, Heydon K, Chu JH, Walsh TJ, Steinbach WJ: Epidemiology, outcomes, and costs of invasive aspergillosis in immunocompromised children in the United States, 2000. Pediatrics 2006, 117:e711-e716.

8. Safdar A: Difficulties with fungal infections in acute myelogenous leukemia patients: immune enhancement strategies. Oncologist 2007, 12(suppl 2):2-6.

9. Frampton JE, Scott L: Posaconazole: a review of its use in the prophylaxis of invasive fungal infections. Drugs 2008, 68:993-1016

10. Cornely OA, Maertens J, Winston DJ, Perfect J, Ullmann AJ, Walsh TJ, et al: Posaconazole vs. fluconazole or itraconazole prophylaxis in patients with neutropenia. N Engl J Med 2007, 356:348-359.

11. Ullmann AJ, Lipton JH, Vesole DH, Chandrasekar P, Langston A, Tarantolo SR, et al: Posaconazole or fluconazole for prophylaxis in severe graft-versus-host disease. N Engl J Med 2007, 356:335-347.

12. Maertens JA, Frere P, Lass-Florl C, Heinz W, Cornely OA: Primary antifungal prophylaxis in leukaemia patients. Eur I Cancer Suppl 2007, 5:43-48.

13. Meunier F, Lukan C: The First European Conference on Infections in Leukaemia-ECIL1: a current perspective. Eur J Cancer 2008, 44:2112-2117.
14. National Comprehensive Cancer Network: Prevention and treatment of cancer-related infection. NCCN Clinical Practice Guidelines in Oncology. [http://www.nccn.org/professionals/physician_gls/PDF/infections.pdf], V.1.2008.

15. Walsh T, Anaissie E, Denning D, Herbrecht R, Kontoyiannis D, Marr K, et al: Treatment of aspergillosis: clinical practice guidelines of the Infectious Diseases Society of America. Clin Infectious Dis 2008, 46:327-360.

16. Ess SM, Schneeweiss S, Szucs TD: European healthcare policies for controlling drug expenditure. Pharmaco Econ 2003, 21:89-103.

17. Chambers M, Hutton J, Nuitjen M: Budget impact analysis for health technology appraisal: development and application within the NICE appraisal process. J Clin Excellence 2002, 4:203-206.

18. Slavin M, Fastenau J, Sukarom I, Mavros P, Crowley S, Gerth WC: Burden of hospitalization of patients with Candida and Aspergillus infections in Australia. Int J Infect Dis 2004, 8:111-120.

19. Olaechea PM, Palomar M, León-Gil C, Alvarez-Lerma F, Jordá R, Nolla-Salas J, et al: EPCAN Study Group. Economic impact of Candida colonization and Candida infection in the critically ill patient. Eur J Clin Microbiol Infect Dis 2004, 23:323-330.

20. Alvarez-Lerma F, Nicolás-Arfelis JM, Rodríguez-Borregán JC, Díaz-Regañón J, Sa-Borges M, García-López F, et al: Clinical use and tolerability of voriconazole in the treatment of fungal infections in critically ill patients. J Chemother 2005, 17:417-427.

21. Wenzel R, Del Favero A, Kibbler C, Rogers T, Rotstein C, Mauskopf J, et al: Economic evaluation of voriconazole compared with conventional amphotericin B for the primary treatment of aspergillosis in immunocompromised patients. J Antimicrob Chemother 2005, 55:352-361.

22. Kuderer NM, Dale DC, Crawford J, Cosler LE, Lyman GH: Mortality, morbidity, and cost associated with febrile neutropenia in adult cancer patients. Cancer 2006, 106:2258-2266.

23. Cagatay AA, Cosan F, Karadeniz A, Besısık SK, Ozsut H, Nalcaci M, et al: The clinical and pharmacoeconomic analysis of invasive aspergillosis in adult patients with haematological diseases. Mycoses 2008, 51:328-335.

24. Wingard JR, Kubilis $P$, Lee $L$, Yee $G$, White $M$, Walshe L, et al: Clinical significance of nephrotoxicity in patients treated with amphotericin B for suspected or proven aspergilosis. Clin Infect Dis 1999, 29:1402-1407.

25. Wingard JR, Herbrecht R, Mauskopf J, Schlamm HT, Marciniak A, Roberts CS: Resource use and cost of treatment with voriconazole or conventional amphotericin B for invasive aspergillosis. Transpl Infect Dis 2007, 9:182-188.

26. Penack O, Reinhold T, Thiel E, Blau IW: Cost-benefit assessment of antifungal prophylaxis with liposomal amphotericin B in neutropenic patients. Onkologie 2007, 30:621-626.

27. de Vries R, Daenen S, Tolley K, Glasmacher A, Prentice A, Howells S, et al: Cost effectiveness of itraconazole in the prophylaxis of invasive fungal infections. PharmacoEconomics 2008, 26:75-90.

28. Stam WB, O'Sullivan AK, Rijnders B, Lugtenburg E, Span LF, Janssen JJ, et al: Economic evaluation of posaconazole versus standard azole prophylaxis in high risk neutropenic patients in the Netherlands. Eur J Haematol 2008, 81:467-474.

29. López-Bastida J, Oliva J, Antoñanzas F, García-Altés A, Gisbert R, Mar J, PuigJunoy J: Spanish recommendations on economic evaluation of health technologies. Eur J Health Econ 2010, 11:513-520.

30. Briggs A, Sculpher M: An introduction to Markov modelling for economic evaluation. Pharmaco Econ 1998, 13:397-409.

31. Spanish National Statics Institute. [http://www.ine.es].

32. National Cancer Institute (NCI): SEER Cancer Statistics Review 1975-2003. Age-adjusted SEER incidence and US death rates and 5-year relative survival rates. 2006

33. Kantarjian $\mathrm{H}$, Beran $\mathrm{M}$, Cortes J, O'Brien $\mathrm{S}$, Giles F, Pierce $\mathrm{S}$, et al: Long-term follow-up results of the combination of topotecan and cytarabine and other intensive chemotherapy regimens in myelodysplastic syndrome. Cancer 2006, 106:1099-1109.

34. General Spanish Council of Pharmacists. BOT database of pharmaceutical prices [http://www.botplusweb.portalfarma.com]

35. Gisbert R, Brosa M, [CD-ROM database]: Healthcare Reference Costs. Barcelona: Centre d'Estudis en Economía de la Salut i de la Política Social; 2005, SOIKOS Version 2.2.

36. Grau Cerrato S, Mateu de Antonio J, Soto Alvarez J, Muñoz Jareño MA, Salas Sánchez E, Marín-Casino M, et al: Economic evaluation of 
voriconazole versus amphotericin $B$ in the treatment of invasive aspergilosis. Farm Hosp 2005, 29:5-10.

37. Gold MR, Siegel JE, Russell LB, Weinstein MC: Cost-effectiveness in Health and Medicine New York: Oxford University Press; 1996.

38. Sacristán JA, Oliva J, Del Llano J, Prieto L, Pinto JL: What is an efficient health technology in Spain? Gac Sanit 2002, 16:334-343.

39. Collins CD, Ellis JJ, Kaul DR: Comparative cost-effectiveness of posaconazole versus fluconazole or itraconazole prophylaxis in patients with prolonged neutropenia. Am J Health-Syst Pharm 2008, 65:2237-2243.

40. O'Sullivan AK, Pandya A, Papadopoulos G, Thompson D, Langston A, Perfect J, Weinstein MC: Cost-effectiveness of posaconazole versus fluconazole or itraconazole in the prevention of invasive fungal infections among neutropenic patients in the United States. Value Health 2009, 12:666-673.

41. Greiner RA, Meier Y, Papadopoulos G, O'Sullivan AK, Imhof A: Costeffectiveness of posaconazole compared with standard azole therapy for prevention of invasive fungal infections in patients at high risk in Switzerland. Oncology 2010, 78:172-180.

42. Tahami AA, O'Sullivan AK, Papadopoulos G: Posaconazole versus standard azole therapy in the prophylaxis against invasive fungal infections among high-risk neutropenic patients in Canada: a cost-effectiveness analysis. 18th European Congress of Clinical Microbiology and Infectious Diseases. European Society of Clinical Microbiology and Infectious Diseases (ESCMID). Barcelona, Spain, 19-22 April 2008. Abstract number: P1029

43. Thalheimer M, Cornely OA, Hoppe-Tichy T, Schuler U, Knoth H, Kiehl M, et al: Pharmaco-economic analyis of posaconazole versus standard azole prophylaxis in high-risk neutropenic AML/MDS patients in Germany. 18th European Congress of Clinical Microbiology and Infectious Diseases. European Society of Clinical Microbiology and Infectious Diseases (ESCMID). Barcelona, Spain, 19-22 April 2008. Abstract number: P1031.

\section{Pre-publication history}

The pre-publication history for this paper can be accessed here: http://www.biomedcentral.com/1471-2334/12/83/prepub

doi:10.1186/1471-2334-12-83

Cite this article as: Grau et al:: Cost-effectiveness of posaconazole versus fluconazole or itraconazole in the prevention of invasive fungal infections among high-risk neutropenic patients in Spain. BMC Infectious Diseases 2012 12:83.

\section{Submit your next manuscript to BioMed Central and take full advantage of:}

- Convenient online submission

- Thorough peer review

- No space constraints or color figure charges

- Immediate publication on acceptance

- Inclusion in PubMed, CAS, Scopus and Google Scholar

- Research which is freely available for redistribution

Submit your manuscript at www.biomedcentral.com/submit
C Biomed Central 